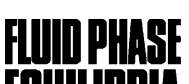

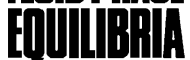

ELSEVIER

Fluid Phase Equilibria 181 (2001) 1-16

www.elsevier.nl/locate/fluid

\title{
Vapor-liquid equilibria of carbon dioxide with diethyl oxalate, ethyl laurate, and dibutyl phthalate binary mixtures at elevated pressures
}

\author{
Kong-Wei Cheng, Muoi Tang ${ }^{1}$, Yan-Ping Chen* \\ Department of Chemical Engineering, National Taiwan University, Taipei, Taiwan, ROC
}

Received 6 September 1999; accepted 21 June 2000

\begin{abstract}
A semi-flow type apparatus was used to measure the vapor-liquid equilibria (VLE) of $\mathrm{CO}_{2}$ with diethyl oxalate, ethyl laurate, and dibutyl phthalate binary mixtures at $308.15,318.15$, and $328.15 \mathrm{~K}$ over the pressure range from 1.4 to $13 \mathrm{MPa}$. New VLE data for $\mathrm{CO}_{2}$ with esters are presented and the Henry's constants were determined from these results. These VLE data were also correlated using the Soave-Redlich-Kwong and the Peng-Robinson equations of state with various types of the van der Waals, composition-dependent and Huron-Vidal mixing rules. It is shown that both equations of state with the van der Waals mixing rules and two adjustable parameters gave satisfactory correlation results. @ 2001 Elsevier Science B.V. All rights reserved.
\end{abstract}

Keywords: Vapor-liquid equilibria; Binary mixture; Data

\section{Introduction}

The experimental determination of phase equilibrium data at high pressures for supercritical fluid systems is important owing to the increasing applications of the dense gases. Carbon dioxide is often used for supercritical fluid extraction because it is non toxic and it has relatively low critical temperature and pressure. The phase equilibrium data at high pressures for carbon dioxide with esters are not adequate in literature [1,2]. More experimental measurements for carbon dioxide with esters are required for thermodynamic modeling and future process design. In this work, a semi-flow apparatus was used to measure the high pressure vapor-liquid equilibria for three binary systems of $\mathrm{CO}_{2}(1)+$ diethyl oxalate (2), $\mathrm{CO}_{2}(1)+$ ethyl laurate (2), and $\mathrm{CO}_{2}(1)+$ dibutyl phthalate (2). Diethyl oxalate $\left(\mathrm{C}_{6} \mathrm{H}_{10} \mathrm{O}_{4}\right)$ is used in pharmaceutical industry and organic synthesis. Ethyl laurate $\left(\mathrm{C}_{14} \mathrm{H}_{28} \mathrm{O}_{2}\right)$ is used in the manufacture

\footnotetext{
* Corresponding author. Fax: +886-2-2362-3040.

E-mail address: ypchen@ccms.ntu.edu.tw (Y.-P. Chen).

${ }^{1}$ Present address: Department of Chemical Engineering, Chinese Culture University, Taipei, Taiwan, ROC.
} 
of cosmetics, food, and pharmaceutical industry. Dibutyl phthalate $\left(\mathrm{C}_{16} \mathrm{H}_{22} \mathrm{O}_{4}\right)$ is used as the plasticizer in organic synthesis. The experiments were carried out at temperatures of 308.15, 318.15, and $328.15 \mathrm{~K}$. The pressure ranged from 1.4 to 13 MPa. The VLE data at each isotherm were then used to evaluate the Henry's law constants. The experimental results were also correlated using the Soave-Redlich-Kwong [3] and the Peng-Robinson [4] equations of state with various mixing rules. Optimal binary parameters are reported and satisfactory correlation results are presented.

\section{Experimental}

\subsection{Chemicals}

Liquefied carbon dioxide was available with purity greater than 99.8 mol\% from San-Fu Chemical Co. (Taiwan). Diethyl oxalate, ethyl laurate, and dibutyl phthalate were purchased from Merck Co. The purity of these chemicals was better than $99 \%$. No further purification of these chemicals was made. The pure compound properties were measured in this study, and the comparison with literature data is shown in Table 1. The refractive indices of the pure compounds were measured at $(293.15 \pm 0.1) \mathrm{K}$ by an Abbe refractometer, Atago 3T, with an accuracy of \pm 0.0001 . The densities of pure chemicals were measured at $(293.15 \pm 0.1) \mathrm{K}$ using the Anton Paar DMA 60/602 density meter with an accuracy of $\pm 1.0 \times 10^{-5} \mathrm{~g} \mathrm{~cm}^{-3}$.

\subsection{Apparatus}

A semi-flow phase equilibrium apparatus, as shown in Fig. 1, was used in this study. The apparatus and experimental procedures were similar to those given in the previous literature [5]. The apparatus consisted of the supercritical fluid feed, the equilibrium and the analysis sections.

Pure $\mathrm{CO}_{2}$ from a cylinder was liquefied through a cooler at $-6.5^{\circ} \mathrm{C}$. It was then compressed by a metering pump (ConstaMetric 3200 P/F, LCD Analytical Inc.), and was heated through a pre-heating coil immersed in a water bath before introducing into the pre-saturation and equilibrium cells. In order to improve the fluid compression, each head of the pump was equipped with a cooling jacket in which aqueous alcohol at $-6.5^{\circ} \mathrm{C}$ was used. A desired pressure was set in the experiment and was maintained at this value by a back pressure regulator (Tescom) during the measurements.

One pre-saturation cell and an equilibrium cell, each with a volume of $300 \mathrm{~cm}^{3}$, were used in this study. The cells (Whitey) were made by stainless steel and were immersed in a water bath. The experimental temperature and pressure were measured using a calibrated quartz thermometer (INS), and a calibrated pressure gauge (Heise). The accuracy for temperature measurement was $\pm 0.1 \mathrm{~K}$, and that for pressure

Table 1

Comparison of the measured refractive indices and densities of pure fluids with literature data

\begin{tabular}{|c|c|c|c|c|c|c|}
\hline \multirow[t]{2}{*}{ Component } & \multicolumn{2}{|c|}{$n^{\mathrm{D}}(293.15 \mathrm{~K})$} & \multicolumn{2}{|c|}{$\rho(293.15 \mathrm{~K})\left(\mathrm{g} \mathrm{cm}^{-3}\right)$} & \multirow[t]{2}{*}{$T_{\mathrm{b}}(\mathrm{K})[17]$} & \multirow[t]{2}{*}{ Purity (mass \%) } \\
\hline & Experiment & {$[17]$} & Experiment & {$[17]$} & & \\
\hline Diethyl oxalate & 1.4102 & 1.4101 & 1.0789 & 1.0785 & 458.85 & $>99.0$ \\
\hline Ethyl laurate & 1.4312 & 1.4311 & 0.8622 & 0.8618 & 544.15 & $>99.0$ \\
\hline Dibutyl phthalate & 1.4918 & 1.4911 & 1.0463 & 1.0465 & 613.15 & $>99.0$ \\
\hline
\end{tabular}




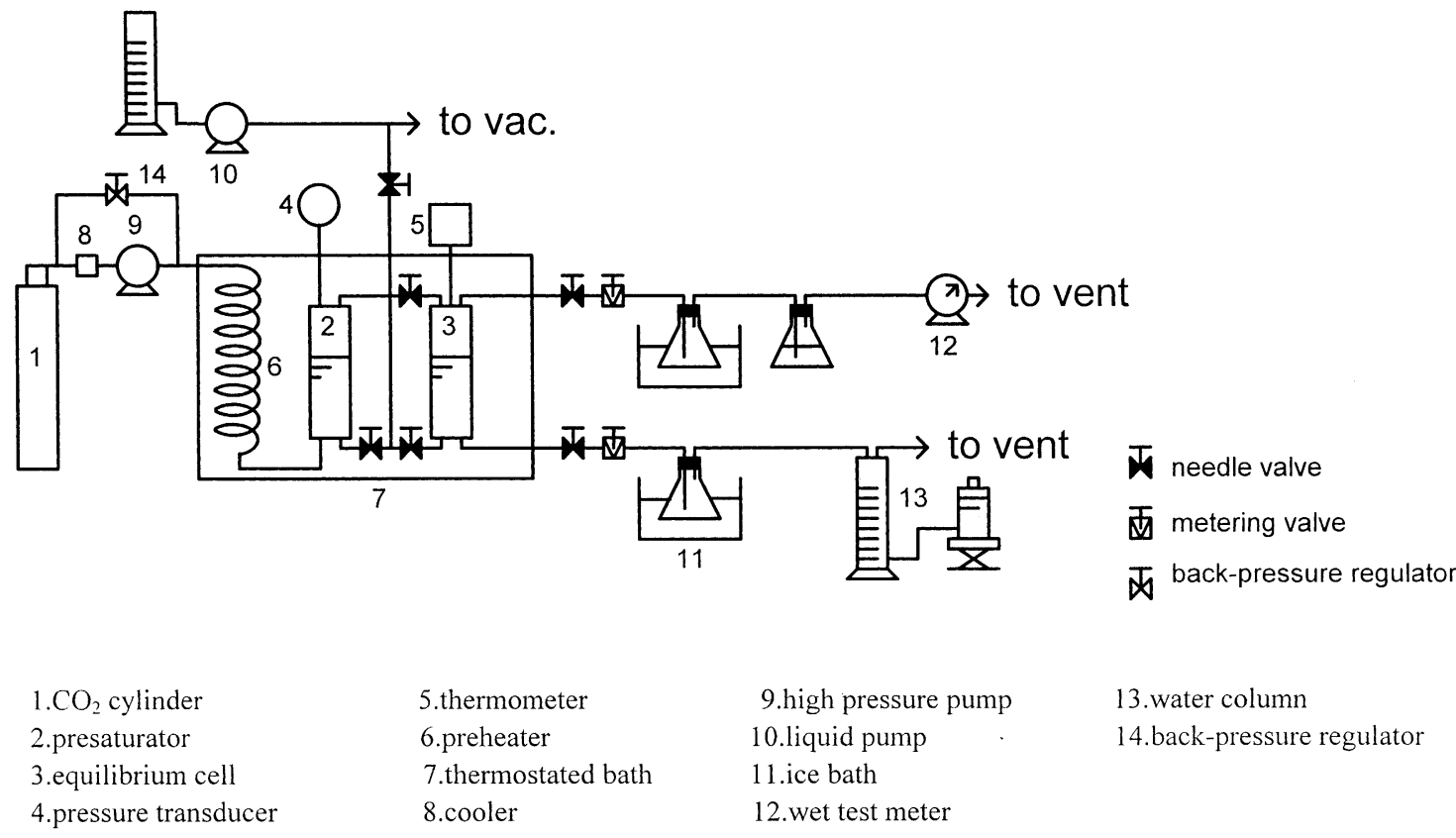

Fig. 1. Schematic diagram of the experimental apparatus.

measurement was $\pm 0.02 \mathrm{MPa}$. The metering valves (Autoclave) and needle valves (Whitey) were also maintained at the experimental temperature to ensure an equilibrium condition.

The solvent (ester) component from either a liquid or vapor sample was collected in a flask cooled by an ice bath. The volume of the solute $\left(\mathrm{CO}_{2}\right)$ in the vapor phase was measured by using a wet test meter (Ritter, TG50), and that of the liquid phase was determined by measuring the volume displaced in a column filled with water. The accuracy for these measurements was better than $\pm 0.25 \%$.

\subsection{Experimental procedures}

Pure liquid solvent was initially fed into the pre-saturation and equilibrium cells. Air in the cells was displaced by the flowing $\mathrm{CO}_{2}$. The two cells were maintained at a constant temperature in a water bath, and $\mathrm{CO}_{2}$ was charged into the cells at a desired pressure. Phase equilibrium was reached after $2 \mathrm{~h}$. Either the vapor or liquid sample was then expanded to atmospheric pressure through the metering valves. The samples were then analyzed by the gravimetric method. The volumes of the solute from the vapor and the liquid phases were measured by using a wet test meter and a water column, respectively. The number of moles of the minor ester component collected in the flask that might vaporize into the gas phase was corrected by using the ideal gas equation of state $n=P^{\mathrm{vp}} / R T$, where $P^{\mathrm{vp}}$ was the vapor pressure of the ester compound and $V$ was the volume of $\mathrm{CO}_{2}$. This correction was very small and its contribution was almost negligible. The reported compositions are the average values of at least three to four repeated measurements. The flow rate of $\mathrm{CO}_{2}$ was $30 \mathrm{l} \mathrm{h}^{-1}$. The flow rates had also been varied from 10 to $45 \mathrm{l} \mathrm{h}^{-1}$, and no change had been observed for the measured compositions. These procedures ensured that the compositions in the liquid or gas phase had reached the equilibrium values. The measured composition 
Table 2

Comparison of the VLE measurement results for the binary mixture of $\mathrm{CO}_{2}(1)+$ toluene (2) at $311.25 \mathrm{~K}^{\mathrm{a}}$

\begin{tabular}{lllll}
\hline Pressure $(\mathrm{MPa})$ & $x_{1}^{\text {exp. }}$ & $x_{1}^{\text {lit. }}$ & $y_{1}^{\text {exp. }}$ & $y_{1}^{\text {lit. }}$ \\
\hline 1.49 & 0.1317 & 0.133 & 0.9930 & 0.993 \\
2.85 & 0.2641 & 0.264 & - & 0.997 \\
4.07 & 0.4068 & 0.406 & - & 0.996 \\
5.58 & 0.6020 & 0.603 & 0.9944 & 0.994 \\
6.94 & 0.8736 & 0.869 & 0.9922 & 0.992 \\
7.34 & 0.9347 & 0.931 & 0.9932 & 0.993 \\
7.74 & - & 0.971 & 0.9927 & 0.993 \\
\hline
\end{tabular}

${ }^{\text {a }}$ From [6].

is with an accuracy better than $\pm 2 \%$ for the minor component in the liquid phase. The accuracy for the minor component in the vapor phase is estimated to be $\pm 1.0 \times 10^{-4}$.

\section{Results and discussion}

The validity of the experimental system was first determined by measuring the vapor-liquid equilibrium for the binary mixture of carbon dioxide and toluene. The experimental results are presented in Table 2

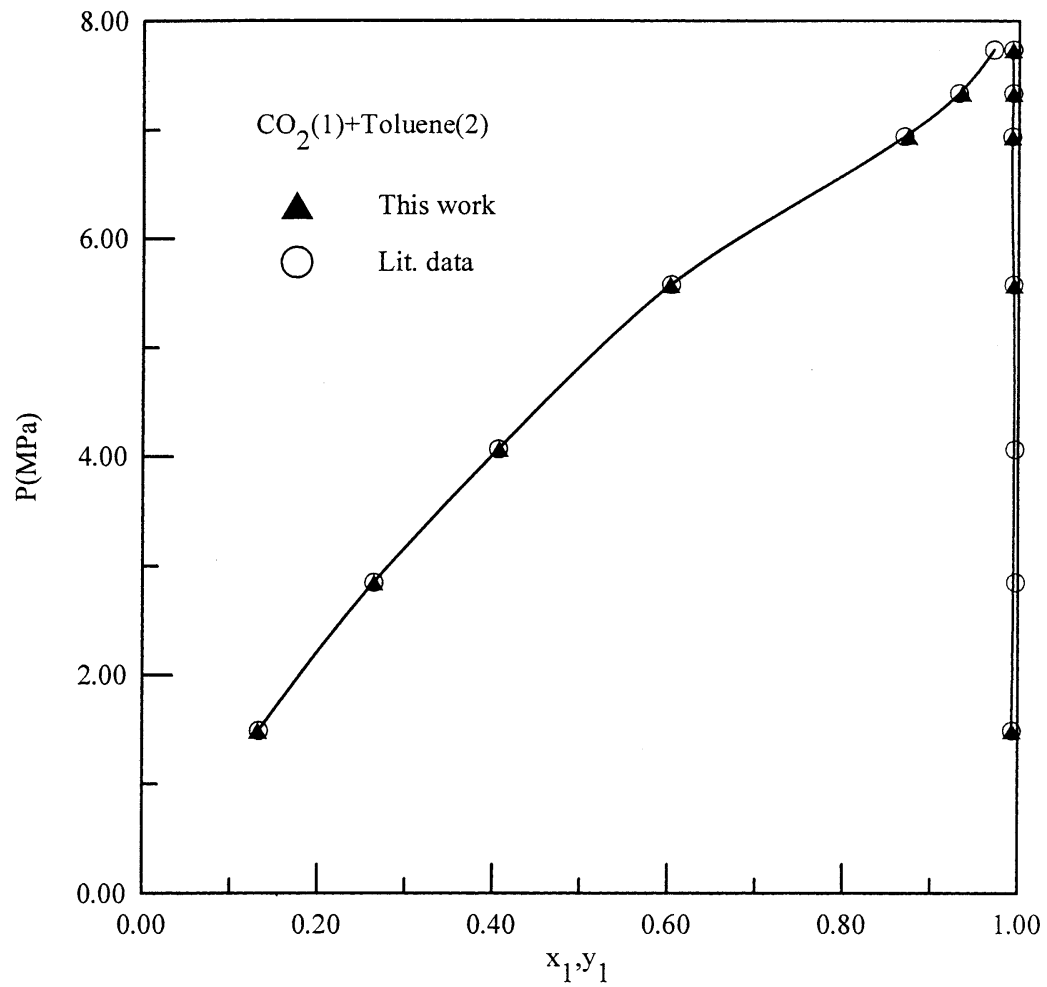

Fig. 2. Comparison of the $P_{x y}$ data for the binary mixture of carbon dioxide (1) + toluene (2) at $311.25 \mathrm{~K}$. 
and Fig. 2. The measured results using the present apparatus are in satisfactory agreement with those in the previous work [6]. The measured equilibrium compositions and the corresponding equilibrium ratios ( $K_{1}$ values) for three binary mixtures of $\mathrm{CO}_{2}$ with diethyl oxalate, ethyl laurate and dibutyl phthalate are presented in Tables 3-5, respectively. Graphical presentations of the experimental results are shown in Figs. 3-5. One way to examine the thermodynamic consistency was the $K$ value method [7,8]. According to this method, the $K_{1}$ values were plotted against pressure for each isotherm of a binary mixture. The slope for each plot should be close to -1 in order to satisfy the thermodynamic consistency. We have tested our experimental data by employing this method, and have found that our results satisfied this empirical requirement.

Table 3

Experimental VLE results for the binary mixture of $\mathrm{CO}_{2}(1)+$ diethyl oxalate (2)

\begin{tabular}{|c|c|c|c|}
\hline \multirow[t]{2}{*}{ Pressure (MPa) } & \multicolumn{2}{|c|}{ Composition } & \multirow[t]{2}{*}{ Equilibrium constant, $K_{1}$} \\
\hline & $x_{1}$ & $y_{1}$ & \\
\hline \multicolumn{4}{|l|}{$T=308.15 \mathrm{~K}$} \\
\hline 1.480 & 0.2222 & 0.9998 & 4.500 \\
\hline 2.858 & 0.4109 & 0.9998 & 2.433 \\
\hline 3.548 & 0.4971 & 0.9998 & 2.011 \\
\hline 4.237 & 0.5887 & 0.9998 & 1.698 \\
\hline 4.793 & 0.6495 & 0.9997 & 1.539 \\
\hline 5.581 & 0.7346 & 0.9996 & 1.361 \\
\hline 6.340 & 0.8355 & 0.9995 & 1.196 \\
\hline 7.029 & 0.8751 & 0.9985 & 1.141 \\
\hline \multicolumn{4}{|l|}{$T=318.15 \mathrm{~K}$} \\
\hline 1.494 & 0.1966 & 0.9997 & 5.085 \\
\hline 2.859 & 0.3522 & 0.9997 & 2.838 \\
\hline 3.617 & 0.4433 & 0.9997 & 2.255 \\
\hline 4.237 & 0.5043 & 0.9997 & 1.983 \\
\hline 4.926 & 0.5657 & 0.9995 & 1.767 \\
\hline 5.685 & 0.6382 & 0.9994 & 1.566 \\
\hline 6.257 & 0.6743 & 0.9993 & 1.482 \\
\hline 6.953 & 0.7522 & 0.9989 & 1.328 \\
\hline 7.753 & 0.8189 & 0.9982 & 1.219 \\
\hline 8.407 & 0.8762 & 0.9980 & 1.139 \\
\hline \multicolumn{4}{|l|}{$T=328.15 \mathrm{~K}$} \\
\hline 1.549 & 0.1828 & 0.9996 & 5.468 \\
\hline 2.859 & 0.3092 & 0.9996 & 3.233 \\
\hline 3.582 & 0.3754 & 0.9994 & 2.662 \\
\hline 4.306 & 0.4469 & 0.9994 & 2.236 \\
\hline 4.995 & 0.5156 & 0.9994 & 1.938 \\
\hline 5.616 & 0.5564 & 0.9991 & 1.796 \\
\hline 7.029 & 0.6780 & 0.9989 & 1.473 \\
\hline 8.028 & 0.7363 & 0.9982 & 1.356 \\
\hline 8.704 & 0.7779 & 0.9973 & 1.282 \\
\hline 9.359 & 0.8208 & 0.9957 & 1.213 \\
\hline 10.096 & 0.8792 & 0.9934 & 1.130 \\
\hline
\end{tabular}


Table 4

Experimental VLE results for the binary mixture of $\mathrm{CO}_{2}$ (1) + ethyl laurate (2)

\begin{tabular}{|c|c|c|c|}
\hline \multirow[t]{2}{*}{ Pressure (MPa) } & \multicolumn{2}{|c|}{ Composition } & \multirow[t]{2}{*}{ Equilibrium constant, $K_{1}$} \\
\hline & $x_{1}$ & $y_{1}$ & \\
\hline \multicolumn{4}{|l|}{$T=308.15 \mathrm{~K}$} \\
\hline 1.480 & 0.2238 & 0.9999 & 4.468 \\
\hline 2.859 & 0.3843 & 0.9999 & 2.602 \\
\hline 3.549 & 0.4687 & 0.9999 & 2.133 \\
\hline 4.238 & 0.5424 & 0.9999 & 1.843 \\
\hline 4.928 & 0.6108 & 0.9999 & 1.637 \\
\hline 5.617 & 0.6822 & 0.9999 & 1.466 \\
\hline 6.307 & 0.7406 & 0.9999 & 1.350 \\
\hline 6.996 & 0.7944 & 0.9999 & 1.259 \\
\hline \multicolumn{4}{|l|}{$T=318.15 \mathrm{~K}$} \\
\hline 1.480 & 0.1993 & 0.9999 & 5.017 \\
\hline 2.859 & 0.3467 & 0.9999 & 2.884 \\
\hline 3.549 & 0.4222 & 0.9999 & 2.368 \\
\hline 4.238 & 0.4826 & 0.9999 & 2.072 \\
\hline 4.928 & 0.5373 & 0.9999 & 1.861 \\
\hline 5.617 & 0.5900 & 0.9999 & 1.695 \\
\hline 7.065 & 0.7073 & 0.9999 & 1.414 \\
\hline 8.306 & 0.7804 & 0.9997 & 1.281 \\
\hline \multicolumn{4}{|l|}{$T=328.15 \mathrm{~K}$} \\
\hline 1.480 & 0.1750 & 0.9999 & 5.714 \\
\hline 2.859 & 0.3133 & 0.9999 & 3.192 \\
\hline 3.549 & 0.3775 & 0.9999 & 2.649 \\
\hline 4.238 & 0.4263 & 0.9999 & 2.346 \\
\hline 5.600 & 0.5351 & 0.9999 & 1.869 \\
\hline 7.082 & 0.6444 & 0.9999 & 1.552 \\
\hline 8.444 & 0.7145 & 0.9997 & 1.399 \\
\hline 9.185 & 0.7443 & 0.9995 & 1.343 \\
\hline 10.099 & 0.7926 & 0.9988 & 1.260 \\
\hline
\end{tabular}

The solubility of carbon dioxide in the liquid phase increased consistently with the decrease of the normal boiling points of esters. An example is shown in Fig. 6 for the three binary mixtures at $328.15 \mathrm{~K}$. Dibutyl phthalate has the highest boiling temperature and has the structure with aromatic group. It is difficult for carbon dioxide to dissolve into dibutyl phthalate. The solubilities of the ester compounds in the vapor phase were not significant at low pressures. These solubilities increased dramatically at equilibrium pressures higher than the critical point of carbon dioxide. The solubilities of various ester compounds in supercritical $\mathrm{CO}_{2}$ at $328.15 \mathrm{~K}$ are presented in Fig. 7.

The Krichevsky-Ilinskaya (KI) equation [9] is generally applicable for the correlation of gas solubility data over a wide concentration range. The Henry's constant can then be evaluated from the regression of the solubility data:

$$
\ln \frac{f_{1}}{x_{1}}=\ln H_{1,2}^{*}+\frac{A\left(x_{2}^{2}-1\right)}{R T}+\frac{V_{1}^{\infty}\left(P-P_{2}^{\text {sat }}\right)}{R T}
$$




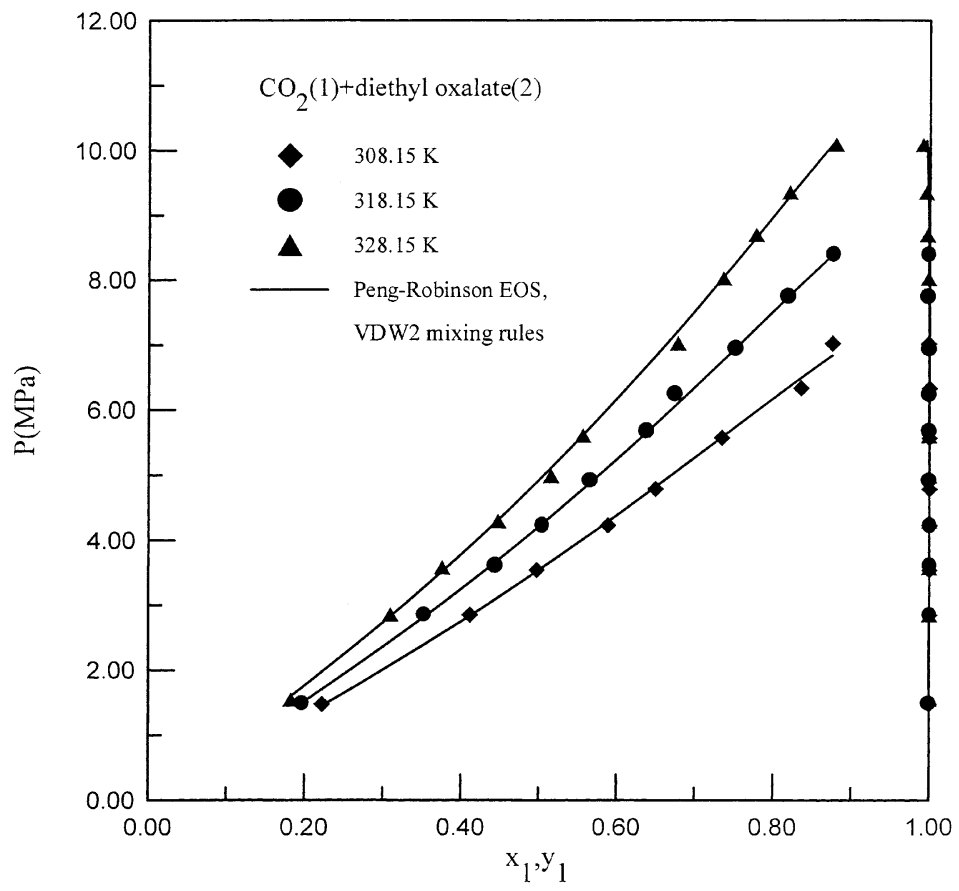

Fig. 3. VLE results of the binary mixture of $\mathrm{CO}_{2}(1)+$ diethyl oxalate (2).

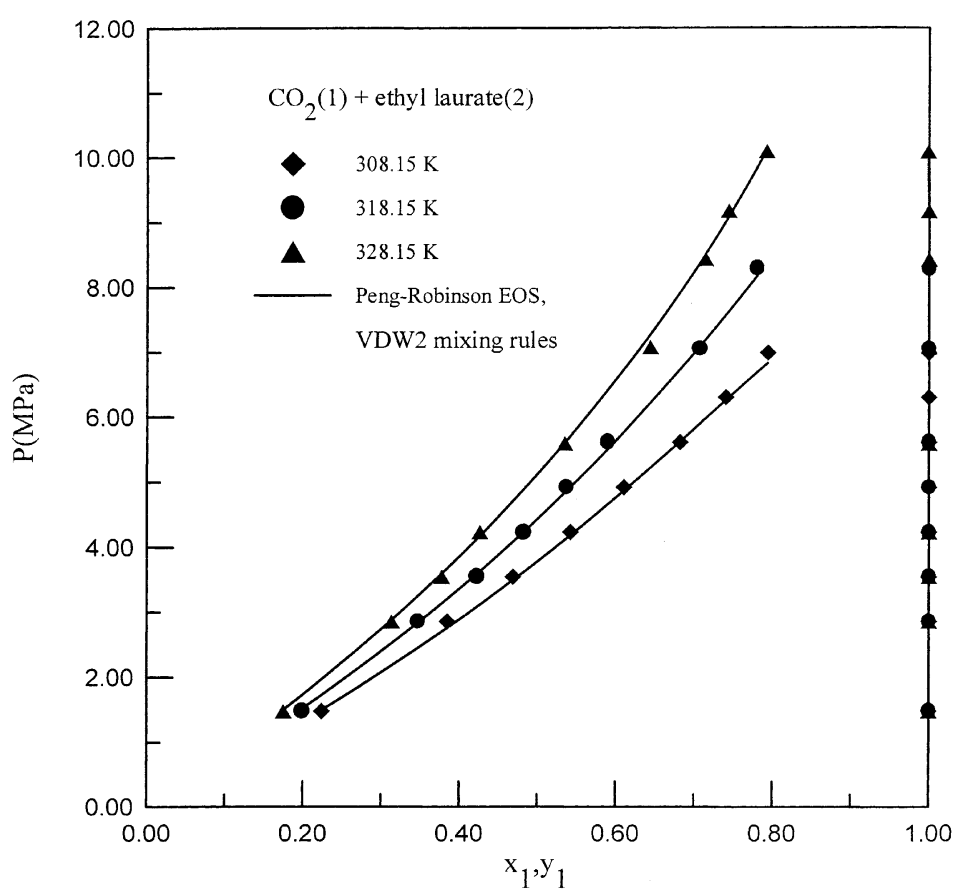

Fig. 4. VLE results of the binary mixture of $\mathrm{CO}_{2}(1)+$ ethyl laurate (2). 
Table 5

Experimental VLE data results for the binary mixture of $\mathrm{CO}_{2}(1)+$ dibutyl phthalate (2)

\begin{tabular}{|c|c|c|c|}
\hline \multirow[t]{2}{*}{ Pressure (MPa) } & \multicolumn{2}{|c|}{ Composition } & \multirow[t]{2}{*}{ Equilibrium constants, $K_{1}$} \\
\hline & $x_{1}$ & $y_{1}$ & \\
\hline \multicolumn{4}{|l|}{$T=308.15 \mathrm{~K}$} \\
\hline 1.480 & 0.1802 & 0.9999 & 5.549 \\
\hline 2.842 & 0.3417 & 0.9999 & 2.926 \\
\hline 3.604 & 0.4341 & 0.9999 & 2.303 \\
\hline 4.238 & 0.4823 & 0.9999 & 2.073 \\
\hline 4.893 & 0.5420 & 0.9999 & 1.845 \\
\hline 5.600 & 0.5977 & 0.9999 & 1.673 \\
\hline 7.100 & 0.7257 & 0.9999 & 1.378 \\
\hline 7.789 & 0.7438 & 0.9997 & 1.344 \\
\hline \multicolumn{4}{|l|}{$T=318.15 \mathrm{~K}$} \\
\hline 1.584 & 0.1647 & 0.9999 & 6.071 \\
\hline 2.877 & 0.3067 & 0.9999 & 3.260 \\
\hline 4.273 & 0.4276 & 0.9999 & 2.338 \\
\hline 5.652 & 0.5329 & 0.9998 & 1.876 \\
\hline 6.996 & 0.6260 & 0.9998 & 1.597 \\
\hline 7.720 & 0.6676 & 0.9998 & 1.498 \\
\hline 8.358 & 0.6946 & 0.9995 & 1.439 \\
\hline 9.358 & 0.7347 & 0.9990 & 1.360 \\
\hline \multicolumn{4}{|l|}{$T=328.15 \mathrm{~K}$} \\
\hline 1.549 & 0.1495 & 0.9999 & 6.688 \\
\hline 2.825 & 0.2635 & 0.9998 & 3.794 \\
\hline 4.204 & 0.3739 & 0.9998 & 2.674 \\
\hline 5.617 & 0.4734 & 0.9997 & 2.112 \\
\hline 6.979 & 0.5533 & 0.9995 & 1.806 \\
\hline 8.323 & 0.6212 & 0.9994 & 1.609 \\
\hline 9.720 & 0.6865 & 0.9985 & 1.454 \\
\hline 11.305 & 0.7428 & 0.9982 & 1.344 \\
\hline 12.546 & 0.7718 & 0.9972 & 1.292 \\
\hline
\end{tabular}

where $H_{1,2}^{*}$ is the Henry's constant at the vapor pressure of the solvent $\left(P_{2}^{\text {sat }}\right), A$ the Margules constant and $V_{1}^{\infty}$ the partial molar volume of the gas at infinite dilution. In this study, $V_{1}^{\infty}$ was estimated from the generalized equation proposed by Brelvi and O'Connell [10] with the modified Rackett model [11] for calculating the liquid density. Carbon dioxide was a dominating component in the gas phase and its fugacity in the gas mixture $\left(f_{1}\right)$ was calculated by employing the Lewis fugacity rule:

$$
f_{1}=f_{1}^{0} y_{1}
$$

where $f_{1}^{0}$ is the fugacity of pure carbon dioxide calculated by the equation reported by Huang et al. [12]. The value of $H_{1,2}^{*}$ and the Margules constant $A$ in the KI equation were evaluated by the least squares algorithm and the results are shown is Table 6 . The average absolute deviation of data regression was small and the solubility data were satisfactorily correlated by the KI equation. The Henry's constants 


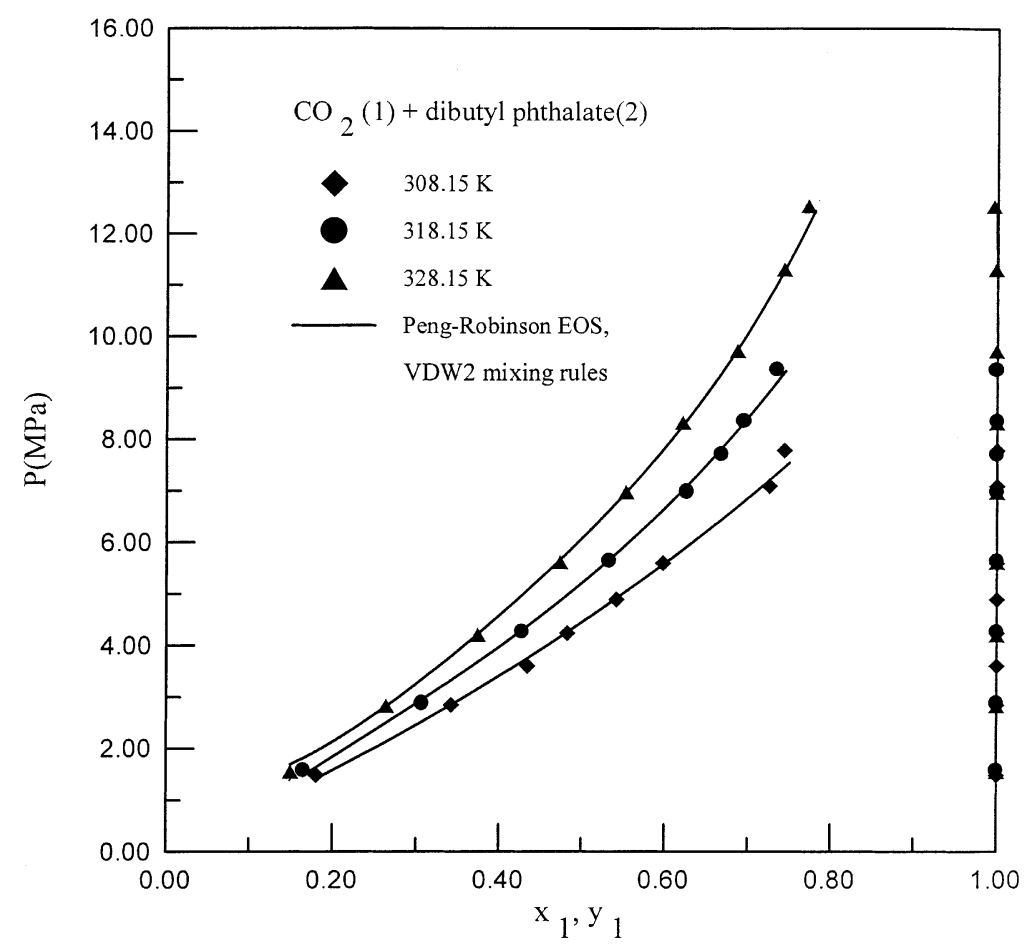

Fig. 5. VLE results of the binary mixture of $\mathrm{CO}_{2}(1)+$ dibutyl phthalate (2).

increased with temperature for a given solvent owing to that the solubility of carbon dioxide decreased with increasing temperature.

The measured vapor-liquid equilibrium data were also correlated using the equation of state method. The Peng-Robinson (PR) equation [4]

$$
\begin{aligned}
P & =\frac{R T}{v-b}-\frac{a}{v(v+b)+b(v-b)} \\
a & =0.45724\left(\frac{R^{2} T_{\mathrm{c}}^{2}}{P_{\mathrm{c}}}\right)\left\{1+\alpha\left[1-\left(\frac{T}{T_{\mathrm{c}}}\right)^{0.5}\right]\right\}^{2} \\
\alpha & =0.37464+1.54226 \omega-0.26992 \omega^{2} \\
b & =\frac{0.07780 R T_{\mathrm{c}}}{P_{\mathrm{c}}}
\end{aligned}
$$

and the Soave-Redlich-Kwong (SRK) equation [3]

$$
P=\frac{R T}{v-b}-\frac{a}{v(v+b)}
$$




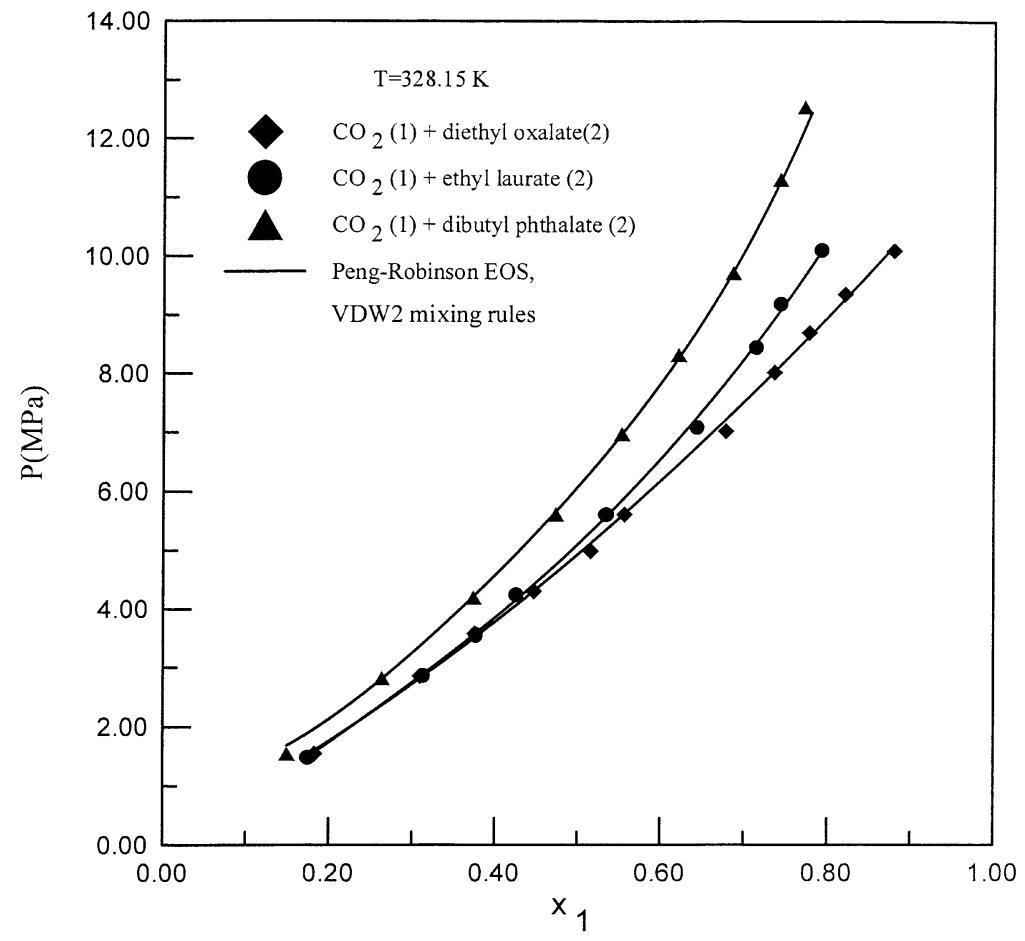

Fig. 6. Solubilities of $\mathrm{CO}_{2}$ in various ester compounds at $328.15 \mathrm{~K}$.

Table 6

Parameters of the KI equation for three binary systems

\begin{tabular}{llcccc}
\hline Systems (1)/(2) & $T(\mathrm{~K})$ & $H_{1,2}^{*}(\mathrm{bar})$ & $A\left(\mathrm{~J} \mathrm{~mol}^{-1}\right)$ & $V_{1}^{\infty}\left(\mathrm{cm}^{3} \mathrm{~mol}^{-1}\right)$ & $\mathrm{AAD}^{\mathrm{a}}(\%)$ \\
\hline $\mathrm{CO}_{2}$ /diethyl oxalate & 308.15 & 71.72 & 909.53 & 45.98 & 2.65 \\
& 318.15 & 80.97 & 844.87 & 47.21 & 3.01 \\
& 328.15 & 92.61 & 916.32 & 48.62 & 3.22 \\
$\mathrm{CO}_{2}$ /ethyl laurate & 308.15 & 68.47 & 616.23 & 57.33 & 2.76 \\
& 318.15 & 74.70 & 477.99 & 58.39 & 2.61 \\
$\mathrm{CO}_{2}$ /dibutyl phthalate & 328.15 & 86.27 & 614.17 & 59.62 & 2.17 \\
& 308.15 & 85.41 & 1010.37 & 56.42 & 1.90 \\
& 318.15 & 97.92 & 1051.07 & 57.20 & 1.30 \\
\hline
\end{tabular}

a Average absolute deviation:

$$
\operatorname{AAD}(\%)=\frac{100}{n} \sum_{k=1}^{n}\left(\frac{\left|x_{1}^{\text {exp }}-x_{1}^{\mathrm{cal}}\right|}{x_{1}^{\exp }}\right)_{k}
$$




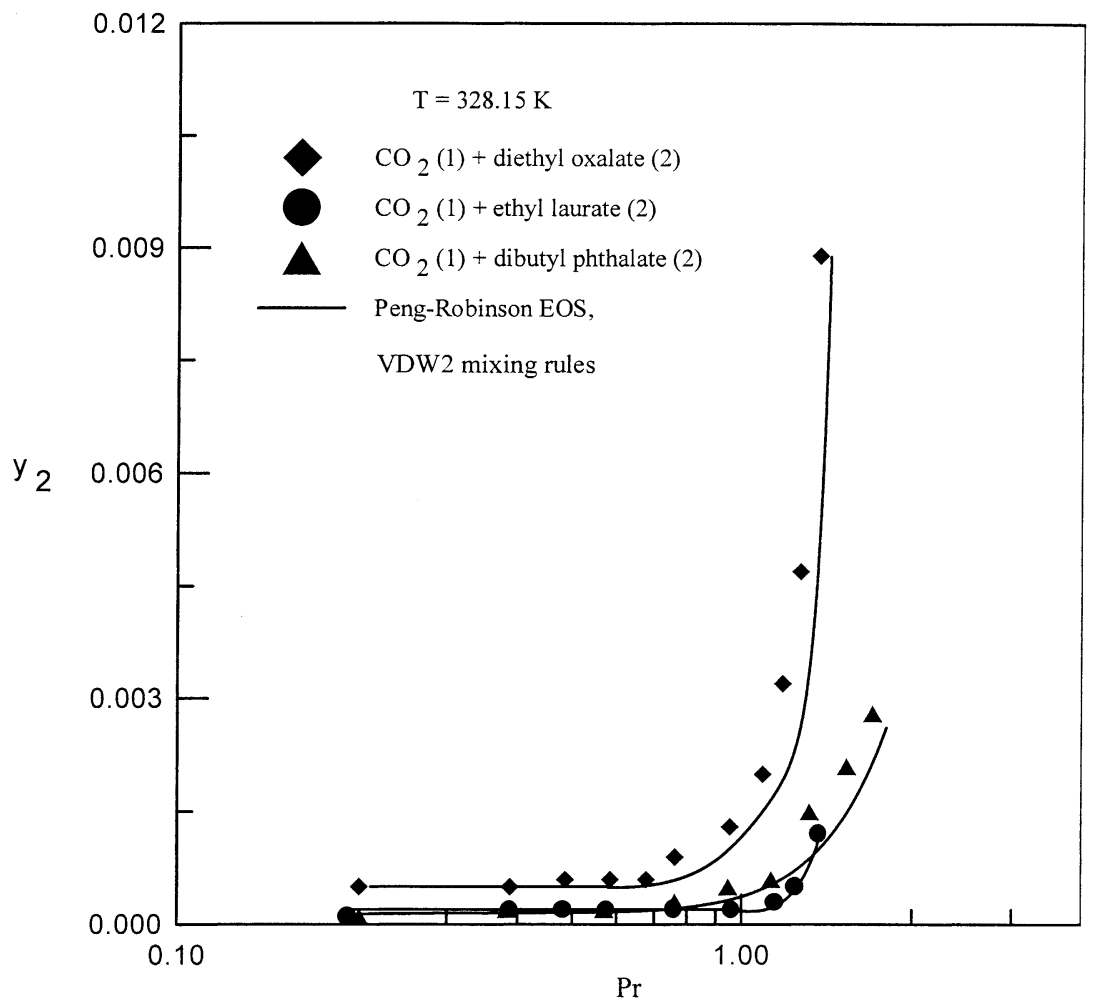

Fig. 7. Solubilities of various ester compounds in supercritical $\mathrm{CO}_{2}$ at $328.15 \mathrm{~K}\left(P_{\mathrm{r}}=P / P_{\mathrm{c}, \mathrm{CO}_{2}}\right)$.

$$
\begin{aligned}
& a=0.42747\left(\frac{R^{2} T_{\mathrm{c}}^{2}}{P_{\mathrm{c}}}\right)\left\{1+\beta\left[1-\left(\frac{T}{T_{\mathrm{c}}}\right)^{0.5}\right]\right\}^{2} \\
& \beta=0.480+1.574 \omega-0.176 \omega^{2} \\
& b=\frac{0.08664 R T}{P_{\mathrm{c}}}
\end{aligned}
$$

were used to correlate the experimental results. Table 7 lists the critical properties and the acentric factors for the pure compounds used in this study.

Various mixing models were applied in this study to evaluate the equation of state parameters for mixtures. For the van der Waals one-fluid (VDW1) mixing rules with one binary parameter, we have

$$
\begin{aligned}
& a_{\mathrm{m}}=\sum \sum x_{i} x_{j}\left(a_{i} a_{j}\right)^{0.5}\left(1-k_{i j}\right) \\
& b_{\mathrm{m}}=\sum x_{i} b_{i}
\end{aligned}
$$

The volume parameter of a mixture can also be evaluated using an additional binary parameter (VDW2 
Table 7

Pure component properties used in this work

\begin{tabular}{llll}
\hline Component & $T_{\mathrm{c}}(\mathrm{K})$ & $P_{\mathrm{c}}(\mathrm{bar})$ & $\omega$ \\
\hline Carbon dioxide & $304.19^{\mathrm{a}}$ & $73.82^{\mathrm{a}}$ & $0.228^{\mathrm{a}}$ \\
Diethyl oxalate & $646.00^{\mathrm{a}}$ & $30.90^{\mathrm{a}}$ & $0.568^{\mathrm{a}}$ \\
Ethyl laurate & $708.40^{\mathrm{b}}$ & $16.26^{\mathrm{b}}$ & $0.777^{\mathrm{c}}$ \\
Dibutyl phthalate & $781.00^{\mathrm{a}}$ & $17.50^{\mathrm{a}}$ & $0.947^{\mathrm{a}}$ \\
\hline
\end{tabular}

${ }^{\mathrm{a}}$ From [18].

${ }^{b}$ From $[19,20]$.

${ }^{\mathrm{c}}$ From [21].

mixing rule):

$$
b_{\mathrm{m}}=\sum \sum x_{i} x_{j} \frac{\left(b_{i}+b_{j}\right)}{2}\left(1-m_{i j}\right)
$$

The binary parameters were taken as temperature-independent in this study, and their optimal values were determined from data regression.

Table 8

Correlated results of experimental VLE data of three binary mixtures using various and EOS mixing rules ${ }^{\mathrm{a}}$

\begin{tabular}{|c|c|c|c|c|c|c|c|c|c|c|}
\hline \multirow[t]{2}{*}{ Mixing rule } & \multicolumn{5}{|c|}{ Peng-Robinson EOS } & \multicolumn{5}{|c|}{ Soave-Redlich-Kwong EOS } \\
\hline & $k_{12}$ & $k_{21}$ & $m_{12}$ & $\begin{array}{l}\text { AAD } P \\
(\%)\end{array}$ & $\begin{array}{l}\mathrm{AAD} y_{1} \\
(\%)\end{array}$ & $k_{12}$ & $k_{21}$ & $m_{12}$ & $\begin{array}{l}\text { AAD } P \\
(\%)\end{array}$ & $\begin{array}{l}\text { AAD } y_{1} \\
(\%)\end{array}$ \\
\hline \multicolumn{11}{|c|}{$\mathrm{CO}_{2}(1)+$ diethyl oxalate $(2)$} \\
\hline VDW1 & 0.012 & & & 1.580 & 0.037 & 0.010 & & & 1.617 & 0.049 \\
\hline VDW2 & 0.008 & & -0.007 & 1.115 & 0.039 & 0.005 & & -0.007 & 1.137 & 0.050 \\
\hline Panagiotopoulos-Reid & 0.025 & 0.011 & & 1.126 & 0.039 & 0.023 & 0.008 & & 1.144 & 0.050 \\
\hline \multicolumn{11}{|l|}{$\mathrm{CO}_{2}(1)+$ ethyl laurate $(2)$} \\
\hline VDW1 & 0.055 & & & 1.763 & 0.011 & 0.062 & & & 1.814 & 0.014 \\
\hline VDW2 & 0.061 & & 0.006 & 1.022 & 0.009 & 0.069 & & 0.006 & 1.036 & 0.012 \\
\hline Panagiotopoulos-Ried & 0.040 & 0.057 & & 1.028 & 0.009 & 0.044 & 0.067 & & 1.042 & 0.012 \\
\hline \multicolumn{11}{|c|}{$\mathrm{CO}_{2}(1)+$ dibutyl phthalate (2) } \\
\hline VDW1 & 0.055 & & & 2.280 & 0.032 & 0.057 & & & 2.081 & 0.037 \\
\hline VDW2 & 0.051 & & -0.004 & 1.360 & 0.036 & 0.053 & & -0.004 & 1.354 & 0.039 \\
\hline Panagiotopoulos-Reid & 0.069 & 0.052 & & 1.359 & 0.036 & 0.070 & 0.054 & & 1.351 & 0.039 \\
\hline
\end{tabular}

${ }^{\mathrm{a}}$ Average absolute deviation of pressure:

$$
\operatorname{AAD} P(\%)=\frac{100}{n} \sum_{i=1}^{n} \frac{\left|P^{\exp }-P^{\mathrm{cal}}\right|_{i}}{P_{i}^{\exp }},
$$

and average absolute deviation of the mole fraction:

$$
\operatorname{AAD} y_{1}(\%)=\frac{100}{n} \sum_{i=1}^{n} \frac{\left|y_{1}^{\exp }-y_{1}^{\mathrm{cal}}\right|_{i}}{y_{1, i}^{\exp }}
$$


Panagiotopoulos and Reid [13] assumed that the binary parameters are composition-dependent (Panagiotopoulos-Reid mixing rule), the mixture volume parameter for an equation of state was determined by Eq. (12), and the mixture energy parameter was written as

$$
a_{\mathrm{m}}=\sum \sum x_{i} x_{j}\left(a_{i} a_{j}\right)^{0.5}\left[1-k_{i j}+\left(k_{i j}-k_{j i}\right) x_{i}\right]
$$

Besides the traditional van der Waals type mixing models, a group contribution mixing model has been proposed by Huron and Vidal [14]. In this mixing model, the excess free energy calculated from an equation of state at an infinite pressure reference state was set equal to that from an activity coefficient model. The NRTL [15] and UNIQUAC [16] activity coefficient models were employed in this study with

Table 9

Correlated results of the experimental VLE data of three binary mixtures by the Huron-Vidal mixing rules with the NRTL and the UNIQUAC activity coefficient models ${ }^{\mathrm{a}}$

\begin{tabular}{|c|c|c|c|c|c|}
\hline EOS & $A_{12}\left(\mathrm{~J} \mathrm{~mol}^{-1}\right)$ & $A_{21}\left(\mathrm{~J} \mathrm{~mol}^{-1}\right)$ & $\alpha$ & $\mathrm{AAD} P(\%)$ & $\mathrm{AAD} y_{1}(\%)$ \\
\hline \multicolumn{6}{|c|}{ NRTL model } \\
\hline \multicolumn{6}{|c|}{$\mathrm{CO}_{2}(1)+$ diethyl oxalate $(2)$} \\
\hline PR & 5189.47 & -3207.26 & 0.2 & 1.33 & 0.04 \\
\hline SRK & 5221.04 & -3408.00 & 0.2 & 1.53 & 0.05 \\
\hline \multicolumn{6}{|c|}{$\mathrm{CO}_{2}(1)+$ ethyl laurate $(2)$} \\
\hline PR & 15465.53 & -4434.32 & 0.2 & 5.51 & 0.01 \\
\hline SRK & 14772.97 & -4555.17 & 0.2 & 5.22 & 0.01 \\
\hline \multicolumn{6}{|c|}{$\mathrm{CO}_{2}(1)+$ dibutyl phthalate (2) } \\
\hline PR & 12498.77 & -4237.51 & 0.2 & 5.49 & 0.05 \\
\hline SRK & 11785.22 & -4357.50 & 0.2 & 5.54 & 0.04 \\
\hline \multicolumn{6}{|c|}{ UNIQUAC model } \\
\hline \multicolumn{6}{|c|}{$\mathrm{CO}_{2}(1)+$ diethyl oxalate (2) } \\
\hline PR & -173.33 & 1880.79 & & 1.04 & 0.04 \\
\hline SRK & -305.64 & 1946.21 & & 1.07 & 0.05 \\
\hline \multicolumn{6}{|c|}{$\mathrm{CO}_{2}(1)+$ ethyl laurate (2) } \\
\hline PR & 1470.35 & 2181.81 & & 1.43 & 0.01 \\
\hline SRK & 1302.83 & 2175.39 & & 1.41 & 0.01 \\
\hline \multicolumn{6}{|c|}{$\mathrm{CO}_{2}(1)+$ dibutyl phthalate (2) } \\
\hline PR & 743.55 & 2641.37 & & 2.42 & 0.04 \\
\hline SRK & 582.80 & 2632.28 & & 2.30 & 0.04 \\
\hline
\end{tabular}

${ }^{\text {a }}$ Average absolute deviation of pressure:

$$
\operatorname{AAD} P(\%)=\frac{100}{n} \sum_{i=1}^{n} \frac{\left|P^{\exp }-P^{\mathrm{cal}}\right|_{i}}{P_{i}^{\exp }},
$$

and average absolute deviation of the mole fraction:

$$
\operatorname{AAD} y_{1}(\%)=\frac{100}{n} \sum_{i=1}^{n} \frac{\left|y_{1}^{\exp }-y_{1}^{\mathrm{cal}}\right|_{i}}{y_{1, i}^{\exp }}
$$


the cubic equations of state. The optimal binary parameters in the NRTL and the UNIQUAC models were regressed from the experimental vapor-liquid equilibrium data. The following objective function was used in data regression:

$$
\mathrm{obj}=\sum\left|\frac{P^{\exp }-P^{\mathrm{cal}}}{P^{\exp }}\right|_{i}+\sum\left|y_{2}^{\mathrm{exp}}-y_{2}^{\mathrm{cal}}\right|_{i}
$$

The optimal binary parameters for various equations of state with the van der Waals type mixing rules are presented in Table 8. It is observed that either the Peng-Robinson or the Soave-Redlich-Kwong equation with van der Waals mixing rules yielded satisfactory results. The optimal NRTL and UNIQUAC parameters regressed from the Huron-Vidal method are shown in Table 9. The results show a relatively larger deviation than those from the van der Waals mixing rules. Graphical presentations of the calculated results from the Peng-Robinson equation of state with the VDW2 mixing rules are also shown in Figs. 3-5.

\title{
4. Conclusion
}

The vapor-liquid equilibrium data of three binary systems of carbon dioxide with diethyl oxalate, ethyl laurate, and dibutyl phthalate are reported at $308.15,318.15$, and $328.15 \mathrm{~K}$ and pressures up to $13 \mathrm{MPa}$. The experimental data satisfy the thermodynamic consistency test. The KI equation was used to correlate the experimental data and the Henry's constants were determined. The Peng-Robinson and Soave-Redlich-Kwong equations of state with various mixing models were also used to correlate the experimental data. It shows that both the Peng-Robinson and Soave-Redlich-Kwong equations of state with the van der Waals mixing rules and two optimally fitted parameters gave satisfactory regression results.

\author{
List of symbols \\ $a, b$ parameters in the equation of state \\ $A$ Margules parameter in the KI equation \\ $f \quad$ fugacity \\ $H_{1,2}^{*} \quad$ Henry's constant at $P_{2}^{\text {sat }}$ \\ $k \quad$ binary interaction parameter in the mixing rule \\ $K \quad$ equilibrium ratio \\ $m$ binary interaction parameter in the mixing rule \\ $n \quad$ number of data points \\ $P$ pressure \\ $R \quad$ gas constant \\ $T$ temperature \\ $v$ molar volume \\ $V \quad$ volume of $\mathrm{CO}_{2}$ \\ $x \quad$ mole fraction of liquid phase \\ $y \quad$ mole fraction of vapor phase \\ Subscripts \\ $b \quad$ normal boiling point \\ c critical properties
}




\title{
$i, j \quad$ component $i$ or $j$ \\ $m$ mixture \\ 1,2 component 1 or 2
}

\author{
Superscripts \\ cal calculated value \\ exp experimental data \\ sat saturated condition \\ vp vapor pressure
}

\section{Acknowledgements}

The authors are grateful to the National Science Council, Republic of China, for supporting this research.

\section{References}

[1] I. Wichterle, J. Linek, Z. Wagner, H.V. Kehiaian, Vapor-Liquid Equilibrium Bibliographic Database, ELDATA SARL, Montreal, 1993.

[2] Z. Wagner, Vapour-liquid equilibrium at high pressure in the system containing carbon dioxide and propyl acetate, Fluid Phase Equilibria 110 (1995) 175-182.

[3] G. Soave, Equilibrium constants from a modified Redlich-Kwong equation of state, Chem. Eng. Sci. 27 (1972) $1197-1203$.

[4] D.Y. Peng, D.B. Robinson, A new two constant equation of state, Ind. Eng. Chem. Fundam. 15 (1976) 59-64.

[5] R.J. Lee, K.C. Chao, Extraction of 1-methylnaphthalene and $m$-cresol with supercritical carbon dioxide and ethane, Fluid Phase Equilibria 43 (1988) 329-340.

[6] H.J. Ng, D.B. Robinson, Equilibrium phase properties of the toluene-carbon dioxide system, J. Chem. Eng. Data 23 (1978) 325-327.

[7] D.E. Matschke, G. Thodos, Vapor-liquid equilibria for the ethane-propane system, J. Chem. Eng. Data 7 (1962) $232-234$

[8] T. Sato, T. Sugeta, N. Nakazawa, K. Otake, M. Satom, K. Ishihara, M. Kato, High pressure of vapor-liquid and vapor-liquid-liquid equilibria for system containing supercritical carbon dioxide, water and furfural, Fluid Phase Equilibria 108 (1995) 293-303.

[9] I.R. Krichevsky, A.A. Ilinskaya, Partial molar volumes of gas dissolved in liquids (the thermodynamics of dilute solution of nonelectrolytes), Acta Physicochim. U.S.S.R. 20 (1945) 327-348.

[10] S.W. Brelvi, J.P. O'Connell, Corresponding state correlation for liquid compressibility and partial molar volume of gases at infinite dilution in liquids, AIChE J. 18 (1972) 1239-1243.

[11] C.F. Spencer, R.P. Danner, Improved equation for prediction of saturated liquid density, J. Chem. Eng. Data 17 (1972) 236-241.

[12] F.H. Huang, M.H. Li, L.L. Lee, K.E. Starling, F.T.H. Chung, An accurate equation of state for carbon dioxide, J. Chem. Eng. Jpn. 18 (1985) 490-496.

[13] A.Z. Panagitopoulos, R.C. Reid, New mixing rule for cubic equation of state for highly polar asymmetric systems, ACS Symp. Ser. 300 (1986) 571-582.

[14] M.J. Huron, J. Vidal, New mixing rules in simple equation of state for representing vapor-liquid equilibria of strongly non-ideal mixtures, Fluid Phase Equilibria 3 (1979) 255-271.

[15] H. Renon, J.M. Prausnitz, Local compositions in thermodynamic excess functions for liquid mixture, AIChE J. 14 (1968) $135-144$.

[16] D.S. Abrams, J.M. Prausnitz, Statistical thermodynamic of liquid mixture: a new expression for the excess Gibbs energy of partly or completely miscible system, AIChE J. 21 (1975) 116-128.

[17] D.R. Lide, H.P.R. Frederikse, CRC Handbook of Chemistry and Physics, 75th Edition, CRC Press, Boca Raton, FL, 1994. 
[18] T.E. Daubert, R.P. Danner, Physical and Thermodynamic Properties of Pure Chemicals: Data Compilation, Hemisphere Publishing, New York, 1989.

[19] D. Ambrose, Correlation and Estimation of Vapor-Liquid Critical Properties. I. Critical Temperature of Organic Compounds. NPL Report Chem. 92, National Physical Laboratory, Teddington, UK, September 1978.

[20] D. Ambrose, Correlation and Estimated of Vapor-Liquid Critical Properties. II. Critical Pressure and Volume of Organic Compounds. NPL Report Chem. 98, National Physical Laboratory, Teddington, UK, 1979.

[21] B.I. Lee, M.G. Kesler, A generalized thermodynamic correlation based on three-parameter corresponding states, AIChE J. 21 (1975) 510-527. 